\title{
Spotlight on measles 2010: Measles outbreak in a mainly unvaccinated community in Essen, Germany, March - June 2010
}

\author{
H Roggendorf (hedwig.roggendorf@gesundheitsamt.essen.de) ${ }^{1}$, A Mankertz $^{2}$, R Kundt $^{1}$, M Roggendorf ${ }^{3}$ \\ 1. District Health Office, Essen, Germany \\ 2. National Reference Center for Measles, Mumps, Rubella, Robert Koch Institute, Berlin, Germany \\ 3. Institute of Virology, University Duisburg-Essen, Germany
}

Citation style for this article:

Roggendorf H, Mankertz A, Kundt R, Roggendorf M. Spotlight on measles 2010: Measles outbreak in a mainly unvaccinated community in Essen, Germany, March June 2010. Euro Surveill. 2010;15(26):pii=19605. Available online: http://www.eurosurveillance.org/ViewArticle.aspx?Articleld=19605

Article published on 1 July 2010

On 15 March 2010, a case of measles was reported to the District Health Office in Essen. In total 71 cases occurred from 15 March to 19 May (four cases hospitalised), with the majority linked to a Waldorf school. Only one case had been vaccinated twice, two cases had been vaccinated once. Immediate and consequent exclusion of non-immune children from classes for two weeks as well as the adjacent spring break prevented the wider spread of the virus.

\section{Introduction}

Measles outbreaks occurred in Germany in recent years $[1,2]$ despite the recommendation of the German Standing Committee on Vaccination (STIKO) to vaccinate all children with two doses of the measles-mumpsrubella (MMR) vaccine, according to the vaccination schedule. Vaccinations are not mandatory in any of the German laender but vaccination cards are routinely checked at a medical examination at school entry.

The last major measles outbreak in Germany in 2006 [2] involved 2,300 cases. During this outbreak, 414 (18\%) of the infected children in the town of Duisburg (North Rhine Westphalia) were hospitalised and two died with severe encephalitis. Since then, information and vaccination programmes were enforced in Germany and the number of reported cases declined to 574 in 2009 [3]. In 2008, countrywide vaccination coverage for measles (with two doses) in six-year-olds was $89 \%$ [4] whereas in Essen, vaccination coverage was $92 \%$ in the age group 11-13 years (unpublished data).

\section{Outbreak description}

On 15 March 2010 one serologically confirmed measles infection in a 13-year-old student and four clinical suspected cases from a Waldorf school in Essen were reported to the District Health Office.

By 19 May 2010, a total number of 71 cases ( 68 children and three adults) were reported to the District Health Office. Up to nine cases were reported on a single day but after the spring break from 29 March to 9 April only a maximum of two cases were reported per day. Twenty-eight pupils (39\%) infected in this outbreak are aged from 11 to 15 years, followed by 19 pupils (27\%) aged between 0 and 5 years, four of whom were not eligible for vaccination. Eighteen children (25\%) are aged between 6 and 10 years and two students between 16 and 20 years. All cases had epidemiological links apart from the three adults (4\%), who were aged over 20 years. For one case the age was not known.

Sixteen of 71 reported cases were serologically confirmed. Genotyping of two isolates by the National Reference Centre revealed Genotype D8. A number of parents refused to have their children tested and this limited the outcome of our investigation.

Three children and one adult were hospitalised with fever and severe rash but they did not develop any major complications.

According to the information received from parents of the 71 cases, 30 could be identified as members of the Waldorf school or kindergarten, 18 as siblings of these members and 20 as visiting doctors who do not recommend vaccination. However, the members of the Waldorf school and their siblings might also visit doctors who do not recommend vaccination. The three adults did not have any link to any of these groups.

Seven siblings have not been seen by a doctor and therefore, have not been reported but they were included in the analysis with the date of onset of symptoms. Another seven cases attended different schools or kindergartens or were too young to attend one. Therefore 25 secondary cases occurred in other schools and kindergartens in unvaccinated children, whose parents refused vaccination. The number of infections through household contacts was 30. One case contracted the disease after vaccination with one dose and another one after vaccination during the incubation period. One of the adults (aged 28 years) had received two vaccinations against measles at the age of two years. All the other 68 cases had not been 
vaccinated at all. Only three cases could not be allocated to one of the groups (Waldorf school, sibling or attending doctor who did not recommend vaccination) indicating that this outbreak was mainly restricted to the above-described groups.

In addition to the 71 cases reported in Essen, five cases reported in neighbouring cities could be traced back to contacts with children from the Waldorf school in Essen. Furthermore, one case reported to the District Health Office in Sonthofen (southern Germany) is linked to a child from Essen who spent his holidays there. Another case from Zwickau (eastern Germany) could have been exposed while visiting a paediatric practice in Essen that did not recommend vaccination but was seeing measles patients at this period.

\section{Public health intervention}

In order to stop this outbreak and to protect the nonimmune children, and since this outbreak involves a school with low vaccination coverage against measles, measures to prevent the spread of the infection according to the national Protection Against Infection Act (Infektionsschutzgesetz) were immediately enforced [6]. This included obligatory control of vaccination certificates and exclusion of non-immune students from classes for 14 days. A firm recommendation for vaccination with a first or second dose against measles was given.

The measures started on 15 March 2010, when the school administration was advised by the District Health Office to hand out leaflets in order to inform the parents about the measles outbreak and the measures planned and recommending that children stay at home if they develop symptoms. Parents were asked to have their children vaccinated if they had not received two doses of MMR; in case of non-compliance, the children were excluded from classes for two weeks. On the following day, staff from the District Health Office (two paediatricians, two health supervisors and two assistants) checked the vaccination certificates of all the pupils attending school on that day, before the beginning of lessons. The control of the vaccination certificates showed that 311 of 762 children ( $41 \%)$ attending the Waldorf school were not vaccinated against the disease or had not had measles before. None of the susceptible students attended classes. However, of the 311 non-vaccinated pupils, $30(10 \%)$ contracted the disease in the following four weeks. Some children had already contracted the disease before the index case but had not been reported earlier. The investigations revealed that the first patient had shown symptoms on 3 March and another six cases followed until the first serologically confirmed case was reported.

Only children who had been immunised against the disease or who had a history of previous disease were allowed to attend lessons. All the others were sent home and the parents were recommended to have their children vaccinated. Following this recommendation, four children were vaccinated. Information on teachers' and other school staff's immunisation status was also available and it was communicated to the District Health Office: all were immune.

The school administration and the teachers were very cooperative in the organisation of the vaccination certificates control. However, the majority of parents indicated clearly that they disagreed with having their children vaccinated against measles.

All the paediatricians in the area were informed by email about the outbreak. The population of Essen was informed via newspapers, Internet and local television. Staff from the District Health Office had several discussions as well as conversations via email with parents who were concerned about the exclusion of their children from school. In the end, the necessity of these measures was agreed upon at a meeting with parents' representatives and staff from the District Health Office held on 25 March 2010.

\section{Discussion and conclusions}

Of the 71 cases in this outbreak, only one had received two doses of MMR and a further two cases had received only one dose. Given the high rate of second-dose MMR vaccination coverage ( $92 \%)$ in six-year-old pupils during the school entry examination of 2009 , as well as in 12-year-olds by annual control of vaccination certificates [7], we hope that the outbreak will stop soon and not extend far beyond the Essen Waldorf community, which has a critical attitude towards vaccination. However, seven new cases were reported in late June in Essen, who have no epidemiological link to the outbreak in the Waldorf community.

Immediate temporary exclusion of children without measles vaccination or naturally acquired immunity from classes has helped to prevent the spread of the virus to a larger number of children. The cases that occurred during spring break had had the incubation period before the break, and the spring break might have contributed to the decrease in the number of newly reported cases.

The virus detected in this outbreak is very similar to a virus imported from India, which caused an outbreak at a Waldorf school in Berlin at the beginning of 2010 [8], but it is not identical (one sequence variation). Therefore, a link to the current outbreak is possible but could not be confirmed.

The goals of the World Health Organization (WHO) to eliminate measles $[9,10]$ cannot be achieved as long as doctors do not recommend vaccination or parents refuse to have their children vaccinated against measles. More efforts and a $95 \%$ coverage with two doses of MMR vaccine in children are needed for measles eradication in Germany, in order to meet the WHO goals [11]. 


\section{Acknowledgements}

We thank all the medical staff and Health officers from the Department of Infectious Diseases Prevention, District Health Office, Essen, for their support.

\section{References}

1. Arenz S, Schmitt HJ, Tischer A, von Kries R. Effectiveness of measles vaccination after household exposure during a measles outbreak: a household contact study in Coburg, Bavaria. Pediatr Infect Dis J. 2005;24(8):697-9.

2. Wichmann O, Hellenbrand W, Sagebiel D, Santibanez S, Ahlemeyer G, Vogt G, et al. Large measles outbreak at a German public school, 2006. Pediatr Infect Dis J. 2007;26(9):782-6.

3. Robert Koch Institut (RKI). Infektionsepidemiologisches Handbuch 2009 [Infectious Diseases Epidemiology Handbook 2009]. Berlin: RKI. 2009. [In German].

4. Robert Koch Institut (RKI). Impfquoten bei der Schuleingangsuntersuchung in Deutschland 2008.[Vaccination rates for the primary school admission health checks in Germany 2008] Epidemiologisches Bulletin 16/2010. Berlin: RKI. 26 April 2010.

5. Spika JSm Wassilak S, Pebody R, Lipskaya G, Deshevoi S, Guris $D$, et al. Measles and rubella in the World Health Organization European Region: diversity creates challenges. J Infect Dis 2003;187:S191-7. PMID:12721913 doi:10.1086/368336

6. Wichmann O, Siedler A, Sagebiel D, Hellenbrand W, Santibanez $\mathrm{S}$, Mankertz A, et al. Further efforts needed to achieve measles elimination in Germany: results of an outbreak investigation. Bull World Health Organ. 2009;87(2):108-15.

7. Roggendorf H, Freynik P, Hofmann F. Erfolgreiche Strategie zur Verbesserung der Impfraten bei Jugendlichen [Improvement Strategy to Increase Vaccination Rates in Adolescents]. Das Gesundheitswesen. 2010. [In press]. [Article in German].

8. Bätzing-Feigenbaum J, Pruckner U, Beyer A, Sinn G, Dinter A, Mankertz A, et al. Spotlight on measles 2010: Preliminary report of an ongoing measles outbreak in a subpopulation with low vaccination coverage in Berlin, Germany, JanuaryMarch 2010. Euro Surveill. 2010;15(13):pii=19527. Available from: http://www.eurosurveillance.org/ViewArticle. aspx?Articleld=19527

9. Kremer JR, Muller CP. Measles in Europe - there is room for improvement. Lancet. 2009;373(9661):356-8.

10. Muscat M, Bang H, Wohlfahrt J, Glismann S, Mølbak K; EUVAC. NET Group. for the EUVAC.net group. Measles in Europe: an epidemiological assessment. Lancet. 2009;373(9661):383-9.

11. World Health Organization Europe. (WHO). Eliminating measles and rubella and preventing congenital rubella infection. WHO European Region strategic plan 2005-2010. Copenhagen: WHO Regional Office for Europe. 2005. Available from: http://www. euro.who.int/_data/assets/pdf_file/0008/79028/E87772.pdf 